\title{
IRIS ANAESTHESIA BY RETROBULBAR INJECTION AND PARALYSIS OF THE ORBICULARIS OCULI BY SEVENTH NERVE BLOCK
}

\author{
BY
}

\section{B. SOMERVILLE-LARGE}

LATE SENIOR RESIDENT OFFICER, MOORFIELDS

IT has been my good fortune during my period of residence at Moorfields to acquire practical experience of retrobulbar injection for the production of iris anaesthesia, and of seventh nerve block to obtain paralysis of the orbicularis palpebrarum, and I feel that some observations on these may be of interest.

\section{Iris Anaesthesia by Retrobulbar Injection}

Indications.-Any condition where complete anaesthesia of the iris is valuable for operative purposes. In those cases especially where iris manipulation is accompanied by considerable pain and where general anaesthesia is frequently employed, as in iridectomy, for sub-acute glaucoma, for relief of tension in iris bombe, and for prolapse of the iris following cataract extraction. Thus pain at the time of operation is removed, and post-anaesthetic vomiting prevented.

\section{Technique}

For Iris Anaesthesia only.-A 2 c.c. hypodermic syringe is used with a $1 \frac{1}{4}$ inch needle. With a needle of this length, injury to the optic nerve is found experimentally to be impossible. 1 c.c. of 4 per cent. novocaine is used, a greater quantity being unnecessary ; in fact, 0.75 c.c. rarely fails to produce perfect anaesthesia. The needle is inserted down and out through the lower lid, the patient being requested to look up, and the needle introduced just over the orbital margin, and passed gently back towards the apex of the orbit to its full length. With the needle in this position, the plunger should be withdrawn to make sure that the injection is not being made into a blood vessel. A small quantity of the fluid is injected during the insertion, and if care be taken to avoid the tarsal plate, this manoeuvre is usually painless. The situation is chosen as the one most likely to bring the point of the needle into the region of the ciliary ganglion lying between the optic nerve and the external rectus. Eight to ten minutes are allowed for full anaesthesia to be obtained.

In Excision or Evisceration of the Globe.-Three injections, each of 2 c.c. of 4 per cent. novocaine, are made similarly to above, down 
and out and down and in through the lower lid and centrally above the middle of the tarsal plate through the upper. Thus 6 c.c. are given in all, this being the maximum amount required; I have performed excisions, with insertion of a glass ball, painlessly with 4 c.c.

Complications.-Two complications have been observed to follow retro-bulbar injections.

The first is haemorrhage occurring in the orbit. This usually comes on simultaneously with the injection, but may be some moments after. It rapidly reaches its maximum and the globe is greatly proptosed, the lids are practically immovable, and the cornea is exposed. The globe is under considerable tension and cannot be pressed back into the orbit. This serious complication has occurred four times in the following series of cases, and all when iridectomy was to be performed for acute rise in intra-ocular tension.

The first case was one with acute rise of tension in a chronic glaucomatous eye. Iridectomy was attempted with the eye in this condition and was accompanied by considerable vitreous loss, the eye ultimately being excised. The second was a case of sub-acute primary glaucoma; posterior sclerotomy was performed immediately and a firm pad and bandage applied. The proptosis was gone when the bandage was removed after 24 hours and the iridectomy was successfully performed under general anaesthesia five days later. The patient was 85 years old and suffered from marked arterio-sclerosis. The third case was one of rise in tension with chronic irido-cyclitis and complicated cataract. Paracentesis of the cornea was carried out, and the eye subsequently trephined successfully four days later. The fourth case was one of rise in tension without irido-cyclitis in association with a mature cataract in a patient aged 78 years. Following orbital haemorrhage no operation was performed, a firm pad and bandage was applied, and the patient sent back to bed. Five days later glaucoma iridectomy was performed with a novocaine injection into Tenon's capsule.

These cases have been mentioned in some detail as it is not always easy to decide what steps to take when this serious complication arises.

The second complication is paralysis or paresis of the inferior rectus. There appears to be a definite tendency for this muscle to be affected. It has been experienced more than once when the injection has been made in a similar manner, only through the upper lid above the middle of the tarsal plate. (This route has been used more frequently of late, and good anaesthesia, with paresis of the superior rectus only, obtained. Complete anaesthesia, however, has not always resulted. The writer is at present inclined to favour 
this method, but has not used it in a sufficient number of cases to estimate its value). Thus paresis occurs in some 30 per cent. of cases, but has never prevented operation being successfully performed.

The completeness of the iris anaesthesia obtained by this method is well demonstrated during the extraction of an intra-ocular foreign body. If this, in process of being drawn into the anterior chamber by the giant magnet, becomes entangled in the iris, the iris retaining it is dragged upon, and the patient is in great suffering, sometimes even verging on collapse. If a retro-bulbar injection is now given, the foreign body is drawn absolutely painlessly out of the iris. This dramatic result was obtained in each case of intra-ocular foreign body in which it was employed.

Retrobulbar Injection for Iris Anaesthesia was used in the following Operations at Moorfields during the first nine months of this Year.

\begin{tabular}{|c|c|c|c|c|c|}
\hline \multicolumn{6}{|l|}{ Cataract extraction ... } \\
\hline Linear extraction & ... & .. & .. & $\ldots$ & 1 \\
\hline Corneo-scleral trephine & $\ldots$ & $\cdots$ & .. & $\ldots$ & 8 \\
\hline Iridectomy in sub-acute $g$ & laucoma.... & $\ldots$ & .. & $\ldots$ & 8 \\
\hline ", secondary $\mathrm{r}$ & ise of tension & & .. & $\cdots$ & 2 \\
\hline Abscission of iris prolapse & following ext & raction & .. & $\cdots$ & 3 \\
\hline "traumatic ir & is prolapse & $\ldots$ & & $\ldots$ & 6 \\
\hline Optical iridectomy $\ldots$ & $\ldots$ & $\ldots$ & ... & $\ldots$ & 2 \\
\hline Iridectomy in iris bombé & $\ldots$ & ... & & $\ldots$ & 4 \\
\hline Removal of intra-ocular $f$ & oreign body & $\ldots$ & $\cdot \cdot$ & $\ldots$ & 5 \\
\hline Saemisch section & $\ldots$ & $\ldots$ & .. & $\ldots$ & 7 \\
\hline
\end{tabular}

The percentage of retrobulbar haemorrhage is thus seen to be small, and of the four cases in which it occurred three were without lasting injurious effects. They all took place in acutely inflamed eyes.

\section{Seventh Nerve Block}

Indications. - When complete paralysis of the orbicularis with consequent inability to squeeze the lids is advantageous.

Technique.-A 2 c.c. hypodermic syringe with a $\frac{3}{4}$ inch needle is used and 2 c.c. of 4 per cent. novocaine is injected. The part of the seventh nerve aimed for is the trunk as it crosses the neck of the mandible. This site is found by placing the forefinger in front of the external auditory meatus and asking the patient to open his mouth wide when the finger is found to dip into a depression caused by the condyle of the mandible moving forwards on to its articular tubercle. On closing the jaw the finger is forced out of the depression by the condyle. The injection is made immediately 
below this landmark until the needle strikes bone, where 1.5 c.c. is injected. The needle is then slid a little way over the zygoma and the rest of the injection is given so as to complete the paralysis of the orbicular branches. This avoids the necessity of injecting the lids themselves and their consequent swelling with difficulty in obtaining complete exposure of the globe. This method rarely fails to produce complete paralysis of the orbicularis palpebrarum.

Complications.-As the injection is made round the main trunk of the nerve, all muscles supplied by it are affected, and one-sided paralysis of the orbicularis oris is experienced. Thus the patient should be warned of the consequent interference with speech. The paralysis has disappeared in six hours.

\section{Conclusions}

Retrobulbar injection, as described, is normally followed by complete iris anaesthesia, which definitely adds to the safety of the operation, and the comfort of the patient.

Orbital haemorrhage following retro-bulbar injection, shows a tendency to occur in inflamed eyes.

Paralysis of the orbicularis oculi is simply and safely obtained by the above method, and squeezing being thereby abolished, operative risk is minimized.

I wish to express my thanks to all the surgeons on the staff of Moorfields for permission to publish these cases.

\section{ANNOTATION}

\section{Libraries of Medical Men and their ultimate disposition}

Our attention has been called to this subject by Dr. Park Lewis, of Buffalo, who bewails the fact that too often the owner makes no provision for his books after his retirement or decease. In such cases, especially after death, no one knows what to do with the books. Frequently they are sold with the practice; sometimes they are dumped on the nearest library; in some cases the executors dispose of them for what they will fetch in the second-hand book market; in other cases the choicer books are distributed among friends and acquaintances, and the remainder assigned to the dust heap.

It must be emphasized that, as Dr. Park Lewis says, in most instances the current books of a doctor's library are almost worthless from a commercial point of view ; but to a medical library they may 